\title{
Language learning as psycho-social support: translanguaging space as safe space in superdiverse refugee settings
}

Article

Accepted Version

Capstick, T. (2020) Language learning as psycho-social support: translanguaging space as safe space in superdiverse refugee settings. Applied Linguistics Review, 11 (4). pp. 701726. ISSN 1868-6311 doi: https://doi.org/10.1515/applirev2018-0036 Available at https://centaur.reading.ac.uk/88392/

It is advisable to refer to the publisher's version if you intend to cite from the work. See Guidance on citing.

To link to this article DOI: http://dx.doi.org/10.1515/applirev-2018-0036

Publisher: De Gruyter

All outputs in CentAUR are protected by Intellectual Property Rights law, including copyright law. Copyright and IPR is retained by the creators or other copyright holders. Terms and conditions for use of this material are defined in the End User Agreement.

$\underline{\text { www.reading.ac.uk/centaur }}$ 
Central Archive at the University of Reading

Reading's research outputs online 


\title{
Tony Capstick*
}

\section{Language learning as psycho-social support: translanguaging space as safe space in superdiverse refugee settings}

\author{
https://doi.org/10.1515/applirev-2018-0036
}

\begin{abstract}
This paper explores language learning for displaced people in the countries bordering Syria and attempts to establish a link between the concept of translanguaging and the concept of safe spaces used by NGOs. The paper uses the term 'displaced people' as it is this feature of being dis-placed that the paper seeks to explore through the lens of superdiversity and its connections to spaces for translanguaging. The concept of superdiversity helps us understand the stratification and multiplication of the processes and effects of migration which lead to heightened complexity, while the concept of translanguaging has been incorporated into this heuristic to help understand how people communicate in these superdiverse settings. The main finding is that monolingual ideologies of language learning pervade the safe spaces which one NGO provides, though the aim is not to single out this one NGO for criticism when the majority of NGOs visited orient to similar monolingual outlooks which disregard home languages at a time when vulnerable adults, adolescents and children need to draw on all of the language resources in their repertoires to make sense of their new surroundings.
\end{abstract}

Keywords: refugee language learning, translanguaging, Syria, Kurdistan region of Iraq

\section{Introduction}

This paper focuses on the transformative power of translanguaging (Wei 2017) in the light of monolingual orientations to language planning which pervade both governmental and non-governmental staff's responses to language learning for displaced people. The paper begins by re-visiting data collected in refugee settings in the winter of 2015-2016 in Jordan, Turkey, the Kurdistan region of Iraq and Lebanon. The initial analysis focused on the concept of

*Corresponding author: Tony Capstick, English Language and Applied Linguistics, University of Reading Faculty of Arts Humanities and Social Science, Reading, UK,

E-mail: tony.capstick@reading.ac.uk 
resilience in relation to language programming in those four countries (Author and Delaney 2016) and will be referred to in this paper as the resilience study. In the current paper, interview data and classroom observations from the fieldwork with governmental and non-governmental agencies working on the humanitarian response to the Syrian refugee crisis are re-visited in order to understand how far the concept of translanguaging space can be aligned with humanitarian work in providing safe spaces for displaced people. In the second part of the paper, the analysis takes up one specific setting and explores how one NGO's attempts to create an 'adolescent friendly space' might benefit from seeing the language use and language learning that goes on in this space as a space for translanguaging.

When NGO staff reported the need to provide safe spaces for refugees to learn in, their main focus was on creating the conditions in which to deliver psycho-social support to the beneficiaries. Language learning classes were increasingly seen by many of these agencies as a potential space in which to deliver this support alongside or embedded in formal language learning, whether in state sector schools in Lebanon which deliver the curriculum in English or French, or NGO classrooms in Erbil Kurdistan where English language lessons are seen as a vehicle for 'post stress attunement' programmes in adolescent friendly spaces. Research carried out by the NGO found that the impact of this approach to psycho-social interventions focused on beneficiaries' increased levels of social trust, diversity of social networks, perceptions of security and safety, and confidence in the future (Panter-Brick et al 2017). These are significant gains given that, in Iraq, one of the main settings for the research presented here, there are approximately three million IDPs of whom a quarter of a million are Syrian refugees (UNHCR 2017). What research has failed to explore is the role of beneficiaries' language use in these interventions and how that language use fits into their ability to recover from trauma.

Refugee settings are always complex; it may be the first time that people living there have been displaced or they may have lived through multiple displacements. Some displaced people want to return home at the earliest opportunity, while others may not have made any decisions about what to do next. This complexity has implications for the language learning programmes discussed in this paper because it makes equitable coverage difficult, particularly as language learning initiatives run the danger of becoming socially 'exclusive' if NGOs and governmental organisations only meet the needs of learners who have previously had access to some form of language learning in the target language of the NGO's language classes. There exists within the field of Sociolinguistics a current concern with this social distribution of language resources as a distinct move away from concerns over 
competence and proficiency. Martin-Rojo (2010) notes that it is the migrant who challenges the Applied Linguist to re-assess this focus on competence and look at how access to language varieties is socially and politically situated. Moreover, in current scholarship on language and migration, it has been suggested that 'academic researchers have a responsibility to find ways of communicating effectively with those who can make a difference to policy and practice' (Blackledge et al. 2015: 8). With this in mind, the current paper examines the possibilities for taking what we know about the rapidly developing concept of translanguaging and applying it to the complexities of displacement in order to connect current research interests in sociolinguistics to the immediate real-world problem of refugee language education programmes. The related case for mother tongue-based bilingual or multilingual education has been made by organisations such as UNESCO since 1953 yet monolingualism in dominant languages is still the norm across the globe (UNESCO 2003). Within this case, the benefits of mother tongue-based education for disadvantaged groups links the use of the mother tongue in education to improved educational outcomes and greater transmission of cultural heritage across generations (ibid). For this reason the current paper connects the use of the mother tongue and the importance of the refugees' own language to the creation of safe spaces as it is specifically disadvantaged groups such as displaced people who need this connection to their linguistic and cultural heritage as they are likely to have experienced disconnection from their home language use and cultural heritage as part of their displacement. Trauma may stem from this and compound the additional traumatic events they may have witnessed or experienced. Some of the effects of trauma include anxiety as well as poor memory, concentration and processing of information, all of which interfere with learning and all of which are mediated by language. Moreover, there is an extensive literature on Foreign Language Anxiety (see Zheng 2008) which posits that the potential of anxiety to interfere with learning is one of the most accepted phenomena in psychology and education (Horwitz 2000: 256). This means that language learning environments need to be safe rather than stressful, Gordon (2011: 2) for example emphasising that 'it is imperative for the ESL field to recognise and investigate trauma as a factor in language learning.' In this paper I therefore take that view that harnessing the benefits of the mother tongue relate not only to enabling learners to connect with their linguistic and cultural heritage at times of disconnection but are also essential to the creation of safe spaces which lay the foundations for reducing anxiety at times of increased trauma as part of the everyday translanguaging that recognises the importance of refugees' own language varieties in language learning. 
To investigate these connections, this paper revisits data analysed for the British Council resilience report in which over 60 agencies working in the four countries were interviewed, and the classes they provide observed. The Language for Resilience report (Author and Delaney 2016) identified five principles which language planners and policymakers might consider when designing the provision of language learning for displaced people and host communities. These principles brought together what we were told and saw in the field with what we know about home language literacy, access to professional training and qualifications, psycho-social support, social cohesion and teacher education. What became very clear during the analysis of these data was that monolingual ideologies of language learning pervaded the respondents' views of language learning as well as the classroom teachers' language teaching strategies and classroom discourse. The current study seeks to explore these orientations in more depth as a means to establish a link between the valorisation of home language use in second language learning by many critical sociolinguists and the concerns of education providers for the psycho-social support of their beneficiaries, as seen in their provision of safe spaces. The section which follows introduces the transnational context of the four countries through an analysis of what agency staff reported in interviews about their work with displaced people before focusing specifically on what staff said about language use and language learning. In the second part of the article the analysis focuses on the situation of one NGO education centre in the Kurdistan region of Iraq. The discussion aims, however, to explore home language use in refugee settings broadly and thus moves on to consider language use in refugee settings beyond the immediate context of Iraq by bringing together the two analysis sections in a discussion of what a translanguaging pedagogy which addresses the needs of displaced people might look like.

\section{Displacement and superdiversity in the humanitarian response to the Syrian refugee crisis}

This section explores what I was told in interviews with humanitarian agency staff in Jordan, Turkey, the Kurdistan region of Iraq and Lebanon about the experiences of forced migrants in those countries. Whereas scholars working within the new paradigm of superdiversity have primarily focused on metropolitan settings in Western European contexts, the current study focuses on non- 
European settings with a particular interest in finding out how the work on superdiversity can be applied to refugee settings where people are displaced and in the potentially enabling role of the superdiversity lens for stimulating language policy and planning. The aim is, therefore, to shift the lens of superdiversity towards displacement. Bringing together work from Sociolinguistics with work from Development Studies invokes a mobile account of multilingualism that is embedded within the unequal distribution of language resources in these settings. This account, I suggest, must not only track language use across national and regional borders but also consider the language learning that occurs in these settings. The superdiversity lens forces us to recognise that the trajectories of learners in these settings are complex; displaced people cannot know how long they will need to, or be able to, stay in their current location and multiple displacement is commonplace. Issues of poverty, and therefore power, are raised when the allocation of resources along these trajectories is deeply rooted in discriminatory practices, not least discriminatory linguistic practices which privilege some language varieties over others. Blommaert and Rampton (2011: 37) put it this way:

'Superdiversity' speaks of rapid change and mobility, and to interrogate this, it is important to incorporate the comparison of old and new datasets and studies, as well as to address the perspectives of different generations and informants. Multi-sited comparison across scales, mediating channel/agencies, and institutional settings is likely to be indispensable in any account concerned with ideology, language and everyday life. But there is also now an opportunity for comparison across nation states and different parts of the world.

Crossing the boundaries of nation-states was a central concern of this study as refugees' trajectories cannot be understood without examining not only their individual journeys and their families' journeys but also the work of the agencies which support them across national borders. Phillimore (2015) found that in order to secure housing for refugees and enhance their employability, there was a need for initiatives that were capable of helping institutions adapt to superdiversity. Taking up the lens of superdiversity at the level of language policy and planning may also enable those agencies working regionally and internationally to seek a new perspective on their increasingly mobile beneficiaries.

The themes which follow are based on a content-based analysis of the interview data from across the four countries. Going beyond an approach which understands interviews as a transparent window into participants' thoughts (Rampton 2006) means accounting for practices which are investigated diachronically with reference to users' trans-local, trans-cultural and trans-lingual trajectories (Blommaert 2010; Pennycook 2012; Canagarajah 2013). 


\subsection{Superdiversity across refugee settings}

The number of home languages and additional languages involved in providing inclusive education in these settings and helping displaced people integrate into primary and secondary host government schools varied widely. The picture that emerged was very much one of trans-local, trans-cultural and trans-lingual trajectories. The respondents were very aware of how displaced people's trajectories cut across locales, cultures and languages. These were not stable, static or unidirectional but rather unstable, dynamic and multidirectional. For example, many children are able to 'integrate' temporarily in different non-governmental school settings by acquiring different local knowledge, and different language varieties. However, language policy related to using dominant languages such as English or French as the medium of instruction requires them to be able to access standard language varieties, which prevents or reduces their ability to fit in. In Lebanon, it was recognised that it would take many years for displaced children to learn English or French to a level of proficiency which would enable them to access the curriculum where these dominant languages are the medium of instruction. A similar situation exists in Turkey where the curriculum is delivered in Turkish, thus raising access barriers to Syrians who do not speak Turkish. However, even in Jordan where Arabic is the medium of instruction, displaced Syrian students are still positioned negatively due to the different varieties of Arabic used and the social position of refugees in the country. Negative perceptions of differences in students' academic level, their different varieties of Arabic, and the discrimination and bullying that result from these attitudes made many agency informants pessimistic about the future of many of these learners. Other issues which affect learner outcomes for displaced people are literacy in the first language and previous educational attainment. Both these issues are related to the education systems of learners' previous schooling, the duration of the conflict and the extent to which the cause of displacement prevented access to education. This was compounded by the conflict that displaced people had experienced and the multiple displacements and level of psycho-social damage this has caused which, respondents commented, impacted on their sense of identity. Learning needs in terms of literacy and language teaching were impacted upon by conflict-affected disruptive behaviour, even when the perceived and actual differences in education attainment between host and displaced communities were not so great. Often, agency staff commented that teachers believed that Syrian education standards were lower, while Syrian refugees in Kurdistan generally believed that they had higher levels of education than their host communities. 
Humanitarian staff understood language and integration into host community settings to be part of displaced families' networks and ties at the local, national and transnational levels. The extent to which integration was encouraged by the host community also had a significant effect on opportunities for integration. This recognition, or lack thereof, by host communities and host governments included political and economic reasons for not wanting to grant citizenship rights or employment rights to temporarily displaced people (the term 'refugee' is not applied to Syrians in Lebanon due to the existing numbers of Palestinian refugees settled there). This also had an impact on decisions about learning new languages and designing new materials and curricula for language learning. Informal camp schools made many attempts to maintain home language use, while integrating into host community schools required the teaching and learning of host languages and catch-up curricula, often emphasising social inclusion. This demonstrated some awareness of language as an issue in accelerated learning programmes which sought to condense three to four years of curricula into much shorter periods. Language learning in these programmes seemed unrealistic as there was little understanding among governmental and non-governmental partners of how long it can take to teach and learn a new language in low-resource environments.

Parental influence had a significant impact on the valuing of education, though this differed considerably across settings. Many NGOs were involved in parent advocacy programmes which aimed to raise awareness of second language learning. In some NGOs this went hand-in-hand with awareness-raising vis-à-vis the importance of first language use in the learning of additional languages, though this did not have a clearly defined pedagogy attached. Some parents saw a relationship between the symbolic importance of home language use for individual and collective identity. Language use was often perceived as an intrinsic part of culture. Occasionally, there was a connection between identity issues and the extent to which parents were literate in their own language. In addition to these beliefs about home language use and identity, many respondents in NGO agencies viewed English as instrumental in helping beneficiaries find a voice for their experiences on the local and international stage. Many commented that English was an important vehicle for dealing with trauma in language lessons which had social inclusion and integration as their objective. Teaching and learning English was also seen as a means of enhancing resilience, and thus also a vehicle for providing access to employment and training.

Finally, the concept of resilience was an over-arching concern for humanitarian staff and is related to the notion of 'safe spaces', which is introduced in the following section. As discussed earlier, it is embedded in the five principles 
outlined in the Language for Resilience (Author and Delaney 2016) report and most clearly linked here to the principle which identifies language learning interventions as vehicles for psycho-social support. Agency staff felt strongly that the effects of trauma are often displayed in learning situations and, in the language programmes I observed, classroom teachers often sought to create safe spaces to work through the effects of trauma with children, adolescents and adults. I found that this was achieved through the provision of creative activities, play and stories in formal and non-formal education. Psycho-social interventions were not always seen as separate from language learning. For example, stories and the arts were often used in language learning to enable learners to express their feelings in the indirect third person with meaningful engagement in language and emotions (Sutherland 1997). This, we argued, could be particularly powerful in the safe space of a second or third language (Costa and De Waele 2013), and therefore we saw this relationship between language, trauma and resilience as a source of protection. However, we also found that the challenge for policymakers and language planners was a lack of knowledge about how language teachers develop their own classroom practices which promote the psycho-social support of learners as part of language learning activities that draw on contemporary methodologies rather than traditional teacher-fronted language immersion approaches. Thus, in addition to the inclusion of teacher education related to translanguaging pedagogies in NGO inhouse training on psycho-social support recommended below, there is also a widespread need for awareness- raising across other stakeholder groups including policy-makers, language planners and academic managers at all levels.

\section{Theoretical framework: Safe spaces as translanguaging spaces}

The theoretical framework for this study draws on critical sociolinguistics (Duchene et al 2013; Heller 207; 2013; Martin-Rojo 2010) and looks across disciplinary boundaries in order to understand the benefits of seeing safe spaces as spaces for translanguaging. I see this interdisciplinary approach aligning with the superdiversity lens as it has been suggested that:

... more than merely describing the diversification of diversity as a result of recent migration, superdiversity has the potential to offer an interdisciplinary perspective on change and complexity in changing social and cultural worlds ... because ... superdiversity aligns itself with critical approaches which reject simplifying and reifying conceptualisations of complex realities along national and/or ethnic lines. (Blommaert et al. 2017) 
The conflict in Syria has led to the displacement of millions of people; by 2017, over 5.2 million people had been displaced from the country of origin, thus an approach which looks across national and ethnic lines is relevant. For the people who make up the research groups for this study, the demands of adjustment to living in new communities after prolonged exposure to the stress of insecurity and loss are marked by rapidly changing social and cultural worlds. Similarly, the host community who find displaced Syrians as their new neighbours also experience increased pressures to accommodate new populations (Panter-Brick et al 2017). Such complexity requires understandings of difference to move away from ethnic, racial and national groupism. The superdiversity orientation enables this, in that it shifts the focus away from binary oppositions of host majority culture versus immigrant minority cultures (Blommaert et al. 2017), as discussed in the previous examples of the trans-lingual and transcultural practices of displaced people. To shift the focus in this way there is an emerging desire to draw on interdisciplinary research and, it has been argued, expand our research imagination and conduct research that is more attentive to marginalised research contexts (Piller and Takahashi 2011: 379).

In this paper, in order to attend to marginalised research contexts, the interdisciplinary perspective I draw on includes approaches from Second Language Education as well as Mother Language Education and Development Education. Drawing on Development Education means harnessing expertise in areas as diverse as formal education system reform, girls' education, life skills and school leadership, as well as pedagogic approaches for large classes, mixed ability cohorts, under-resourced systems and other difficult circumstances. Similarly, humanitarian work covering minimum standards for conflict affected education and work on social inclusion would help to better explain the multiple and complex nature of education in emergencies, about which a great deal is already known. There are also links to be made between social inclusion and inclusive classroom pedagogies related to safe learning environments, child protection and psycho-social support.

This interdisciplinarity is linked to work that has been carried out primarily in psychology when strengthening existing evidence for humanitarian interventions that provide psycho-social support for conflict-affected displaced people. It has been suggested that psycho-social support and mental health programmes have had little robust evaluation in humanitarian settings (Blanchet et al. 2015; Tol et al. 2011), leading to the recommendation that there is an urgent need to strengthen this evidence base (Ager et al. 2014; Panter-Brick et al. 2017). Patel (2014) suggested that this weak evidence base has led to a lack of credibility concerning mental health treatment and prevention. In response, Panter-Brick et al. (2017) compared youth treatment and waiting-list controls over two 
programme cycles of the Advancing Adolescents programme at the NGO which took part in the current study in their Jordan programmes by measuring distress, insecurity, mental health difficulties, post-traumatic stress and prosocial behaviour (Panter-Brick et al. 2017: 1). They did this without accounting for the role of language in their experimental design, though they did find that the Advancing Adolescents programme had beneficial impacts on emotional and behavioural difficulties, as well as symptoms of insecurity and distress (Panter-Brick et al. 2017: 16).

The Profound Stress and Attunement approach taken by the NGO has been described as community-based and nonclinical. The International Child Development Programme (Hundeide 2013) has outlined eight guidelines on which the attunement principles are based. These principles range from establishing verbal and nonverbal emotional dialogue to describing emotional challenges. This approach is a programme of psycho-social care that aims to improve social interactions through participatory approaches and the development of safe emotional spaces (Panter-Brick et al. 2017). The remainder of this section takes its theoretical orientation from concepts which explain how having a language in common with others, that is respected when entering into emotional dialogue, should be a central aspect of dialogue in these safe spaces.

Wei (2011: 1223) has suggested that social spaces for translanguaging are constructed when language users bring together different aspects of their experience, history and environment, as well as their beliefs and attitudes. Bringing together these aspects may then provide the conditions for emotional dialogue and create a space in which post-stress attunement can occur, given that, as Li Wei suggests, translanguaging space has 'its own transformative power because it is forever evolving and combines and generates new identities, values and practices' (Wei 2011: 1223). Translanguaging spaces are therefore spaces which require participatory and prosocial behaviour to generate new values and new identities which occur in interaction with others in and through language. They are pro-social, as individual and group repertoires come together as history and environment are combined in what Pennycook and Otsuji call spatial repertoires, i.e. they are formed through individual life trajectories that link particular repertoires of individuals to the group (Pennycook and Otsuji 2015). It is in this bringing together of repertoires that these spaces can become sites for emotional dialogue where linguistic resources have a direct link to safe spaces.

In the Advancing Adolescents programme at the NGO, structured groupbased activities draw on the Profound Stress and Attunement framework described above by creating a 'safe space' in which extreme and prolonged stress are mediated (Macphail et al. 2017). Given that communicative repertoires and available resources, at a given point in time and space, are subject to the 
contingencies of the space produced (Blackledge et al. 2017), it could be argued that in order to mediate profound prolonged stress, these safe spaces must take account of the communicative repertoires which make up that space. Scholars bring together this notion of spatial repertoires with current work on translanguaging:

... a space created by and for translanguaging practices, a space where multilingual individuals integrate social spaces (and thus 'language codes') that have been formerly practiced separately in different spaces by 'bringing together different dimensions of their personal history, experience and environment, their attitude, belief and ideology, their cognitive and physical capacity into one coordinated and meaningful performance. (Hua et al. 2015: 9)

Safe spaces ensure self-appraisal, self-esteem, positive identity and feelings through self-regulation and, UNICEF argue, they provide a sense of hope, a 'voice' and meaningful engagement and interaction with others (UNICEF 2016). Thus, a safe space can be seen as a space for translanguaging, and vice versa. Teachers and learners use empathy, communication and cooperation in both safe spaces and spaces for translanguaging. Seeing the goal of creating these two spaces as a means to better understand how people communicate when they bring different histories and repertoires into contact (Blackledge et al. 2017: 15) embraces the notion of the safe space.

Translanguaging can, therefore, be transformative in creating safe spaces, with the potential to remove the hierarchy of languaging practices that marginalise some language varieties and speakers of those varieties, speakers who will already be marginalised if they are displaced. Like Conteh and Brock (2011), I see the key to providing safe spaces for bilingual learning being in the relationships that are constructed between learners and their educators and in the transformative power of such relationships, which Cummins (2001) argues must be oriented towards empowerment rather than the re-production of the status quo so that the culture of the classroom can be transformed. However, the theoretical stance in the current paper extends the notion of safe spaces in which all children grow into full participants of a society (in Conteh and Brock's case, the UK society), and it embraces the superdiversity of rapidly changing settings where opportunities for meaning-making and identity construction through language are not embedded in belonging to one nation-state, but rather consist of multiple belongings as displaced persons' trajectories may take them through several nation-states. This expanded notion sees territorially-shaped identities and practices de-territorialized when individuals no longer travel in one direction between their countries of origin and receiving nations, but rather form identifications and affiliations which are both bounded and unbounded in 
transnational processes while at the same time 'transcending the institutional and geographical boundaries of the nation-state' (Smith 2003: 468). This is not to deny the significance of nation-building in the peace-building process in Syria. The sense of creating a common identity connected to a (new) state which is able to keep former enemies integrated into that state is closely related to education; and language, as a marker of identity, has a key role to play (Footit 2012). However, Footit has suggested that using language as a discriminatory tool deprives members of a minority ethnic group of the feeling of belonging to a wider ethnically mixed community and also increases the likelihood that members of the minority ethnic group will harbour feelings of belonging to their specific ethnic group where their language is valued, rather than the wider community, leading to segregation (ibid.).

The approach to translanguaging in classroom settings presented here challenges this use of language as a discriminatory tool and seeks an alternative view which is about a way of being, acting and languaging in social, cultural and political contexts that removes elements of both nation-building and marginalisation for displaced people. For example, Makalela (2017) has demonstrated that, in the context of South Africa, classroom spaces can be transformed when they are reconceptualised as microcosms of societal multilingualism. In these diverse classrooms, where fluid, versatile language practices are encouraged, learners learn together in safe translanguaging spaces. Current sociolinguistic research has shown that linguistic and cultural differences have a negative effect on minorities when they have a weak position in the social structure and have to overcome structural obstacles for their social and economic success (Heller 2010; 2011). When other resources are scarce during periods of displacement, the concept of a safe translanguaging space in which to learn creates the conditions for psycho-social support through the transformative power of language users' shared histories, beliefs and experience.

\section{Methodology}

By 2015, an estimated 40.8 million people were displaced within the borders of their own country due to conflict and violence (UNHCR 2016). The aim of this section of the paper is to describe the methodological framework employed when collecting data in settings populated by displaced people, before moving on to describe the methods of data collection and analysis for exploring how one NGO in particular understands language use in its classrooms for displaced people. 
Displaced people and host communities communicate when they come into contact in rapidly changing settings, and so analysing their communicative practices in terms of wider social processes, ideologies and relations of power meant adopting methods common to Linguistic Ethnography. As such, it was necessary to observe communication practices closely and repeatedly over time. In designing the research, my aim was to account for heightened mobility and complexity by revisiting the data collected in the winter of 2015-2016 to explain the wider context of displacement from Syria. I then carried out two 2-week long visits to one of the NGOs in Erbil from the original study. I have created pseudonyms for the staff I interviewed and observed. The research took place in 2017 and involved classroom observations and interviews with NGO staff and the teachers, known as coaches. These coaches had been part of a year-long weekly remote mentoring scheme which I had set up, where teachers at the University of Reading in the UK mentored the coaches in Erbil, helping with guidance on classroom procedures, activities and teaching strategies. Interpreters and translators have helped me with the data collection and transcription of data, as my research brought me into contact with many people communicating through semiotic repertoires which were not accessible to me. Having visited the region in 20152016 for the Language for Resilience project, I decided to focus on Erbil for the current study as the city is predominantly Kurdish speaking, though the dialect is different from that of the many Kurdish-speaking Syrians who had migrated there. I also wanted to look at an NGO setting. It has recently been recognised that superdiversity research developed predominantly in the context of Western Europe and is currently limited as a Euro-centric or Western-centric notion (Mufwene 2008; Pavlenko 2016; Ndhlovu 2016). However, Blackledge et al. (2017) suggest that 'child superdiversity is gaining independence and is beginning to take steps out into the world'. In this study, this world is that of refugees and internally displaced people who have come to settle in Erbil. Without the resources or access to work across the whole city, the study focuses on two youth centres located in the Khabat and Shawes districts in the Governorate of Erbil. The communities in these districts have lower levels of access to schools than other parts of Erbil and have received influxes of internally displaced people from Mosul in Iraq, as well as refugees from different parts of Syria. The centres' activities that I observed included technical courses, life skills classes, drop-in sessions and community projects. At the Shawes centre there were specific problems around the rental of the building, the high levels of stress that many of the mixed community beneficiaries were experiencing and other international NGOs implementing similar programmes.

A key study here in tracing youth and social change in these centres through the lens of linguistic ethnography was that of Perez-Milans (2015), who suggests 
that adolescents must negotiate a complex set of discursive practices in forming their academic trajectories across unpredictable social networks, communicative genres and regional national boundaries. I took a similar approach when accounting for displaced adolescents who, at the time of writing, had fled conflict areas in Syria and Iraq and were settled in Erbil. This ethnographically-informed approach combines linguistic and ethnographic perspectives with linguistic anthropology (Hymes 1980), as well as interactional sociolinguistics (Gumperz 1982), in order to link what I was told in interviews with what I saw inside and outside the classrooms during the ethnographic phases of data collection with the NGO. Bringing these different fields together is both a methodological and a theoretical challenge. However, De Fina et al. (2017) have suggested that physical or virtual interaction is now the norm between nationalities, ethnicities, languages and cultural modes. They argue that these new norms affect the ways in which people communicate in all contexts of their lives, which therefore requires a rethinking of the concepts and methodologies underlying the practice of sociocultural linguistics (De Fina et al. 2017). This rethinking is demonstrated in the analysis of the interview data in the following section, where I focus on the coaches' beliefs about language use. I took an interpretive approach to analysing the data collected across these research sites in an attempt to provide a fine-grained, ethnographic understanding of diversity as a lived experience in the city, following Copland and Creese (2015), an approach which foregrounded the local and immediate interactions of actors from their point of view and considered how these interactions were embedded in wider social contexts and structures. By taking detailed field notes in these settings, I was able to keep an account of interactions between the host community, refugees and internally displaced people, thereby linking everyday linguistic and cultural practices to wider social processes, ideologies and relations of power in the discourse analysis which follows.

In each of the NGO settings the aim was to make detailed intensive observations of communicative practices inside and outside the classrooms. In the centres this meant observing people in the playgrounds, staff rooms and corridors, as well as attending many of the activities that were provided for the beneficiaries including drama groups, a fathers' group, Arabic lessons, English lessons and the community-based project planning sessions between NGO staff and beneficiaries. I selected key participants in each site, explained the project and gained consent for data collection and use of those data. For the first part of the day in Erbil I wrote observational field notes, then during the afternoon activities I asked participants to attach an audio-recording device with a tie-clip microphone to their clothing and record themselves as I continued to write field notes. I video-recorded interactions in the classrooms where possible, though 
occasionally in the NGO beneficiaries preferred not to be video-recorded. In the afternoons and evenings, I interviewed key participants and stakeholders from the wider community. I took a few photographs and the photographs I did take were rarely of people, as most of the people in these settings are vulnerable adolescents and adults.

\section{Analysis: Language use and language learning in an NGO in Erbil}

Currently, approximately three million Iraqis are displaced, with more than one million of these living in the Kurdistan region (UNHCR 2017). The analysis carried out here seeks to understand how the NGO staff, interviewed in face-to-face meetings in 2017, talk about language use in the English language classrooms of the Advancing Adolescents programme and how they link English language learning to their main aim of providing psycho-social support. The lay coaches who deliver the Advancing Adolescent programme are trained by the NGO to understand how stress physiology affects brain function and how to facilitate experiential learning, but they are not trained in how to use different home languages in their mixed refugee, IDP, host community classrooms and had received just two weeks of English language teacher training before starting their 8-week English courses which are part of the 'technical skills' strand of the programme.

Since the fall of Saddam Hussein, the Kurdish language (Badini dialect) in the Kurdistan region of Iraq has risen in status as a result of changes in political and social power. However, different dialects (Sorani) of Kurdish brought into the region by Syrian Kurds mean that Kurdish remains a minority language, though one with powerful links to group identity for Syrian Kurds. Many Kurds interviewed for this study, regardless of national identity, believed that the preceding period of success against ISIL was their greatest opportunity to push their national aspirations. They feel that their desire for a Kurdish state has been brutally crushed over decades and they were at that time in a situation of strength; Pershmerga fighters successfully pushed back the Islamic State and many Kurds across the region awaited their reward from the central government in Baghdad. The medium of instruction in schools in Kurdistan is therefore highly politicized as Kurdistan wrestles for independence from the Arabic-dominant central government in Baghdad (see Shanks 2016). Different languages compete for space in the education centres visited for this study.

This section of the analysis turns to interviews carried out in spring 2017 with 12 coaches of English. The research question relates specifically to the role 
of home languages in four NGO centres. The coaches were all asked the same questions about language use and language learning, as the research aim was to establish a link between the superdiversity explored in the previous section and the discourses about language use which circulate in this specific NGO by identifying key themes among the analysed instances of discourse in each of the interviews. I then used these discourse topics to select data from the fieldnotes and observational data from inside and outside the classrooms. Drawing on Kryżanowski (2008), I define the basic analytic category 'discourse topic' as 'expressed by several sentences in discourse ... by larger segments of the discourse or by the discourse as a whole' (van Dijk 1984: 56). A discourse topic is, in other words, the salient theme that underlies a series of sentences in the interview data. The topics were addressed by the participants during the interviews, which were primarily framed by questions about home language use in their classrooms. All the discourse topics relate to home language use; this is the macro-topic. In this macro-discourse topic about home language use there are various sub-topics (see Reisigl and Wodak 2001). These are identified below.

\subsection{Discourse topic 1: English first}

In the extract which follows, I am asking Zainab about when she uses home languages in the English language classroom with her mixed Kurdish, Iraqi and Syrian learners.

Tony: When you do see them what do they provide you with? What do they kind of do the NGO mentors?

Zainab: Yes, yesterday I asked him [the mentor] what I have to do in my class about heart contract in the first class session we have to do a heart contract for the students. I asked him if it is necessary to do it in Arabic or in English.

Tony: Yep.

Zainab: If I have any question I tell him.

Tony: Did he say English or in Arabic?

Zainab: He said it depends on my students if their level is good and they can get the idea of heart contract you can do it in English but if their level is somehow not then you can translate you can use Arabic and English.

This discourse topic reflects the common view among NGO staff that the target language, English, should be used first. The orientation to a monolingual ideology in the 'heart contract' goes against the psycho-social aims of establishing a contract among learners which values and respects all of their views and 
opinions but not, it would seem, all their language resources. Full immersion in the target language in the first task of the first lesson also increases the risk of foreign language anxiety (Zheng 2008). This anxiety is exacerbated in the case of learners suffering from PTSD given its negative effects on how refugees process new information such as vocabulary, grammar and pronunciation in the target language (Borrell ND) in the sense that 'second language learning involves a fundamentally traumatic experience for the individual' (Clarke 1976: 377) thus reducing the likelihood of creating a safe space for learning which the use of the learners' own language may have increased.

The extract demonstrates how the home languages of the beneficiaries are seen by the mentor as less significant languages, even in the more directly 'psycho-social' parts of the lesson.

\subsection{Discourse topic 2: 'She has to translate'}

Nadia: What I like that Noor helped me so much and she talked so much, she take the most of time, this is the reason I can't express I can't share, just I translate for my students side translate and it is difficult because maybe take more time to speak in English at first and then she has to translate to Kurdish and then I have to translate to Arabic.

This is not an uncommon discourse among teachers who feel that translation is the default position when students do not understand the target language. In the lesson observations I saw many examples of the coaches using the target language; then, if there was silence or misunderstandings, the coach would translate the target language into the learners' home language. García and Wei (2014: 122) suggest that this is because, in the majority of teacher education institutions globally, learners' multilingualism is an 'after-thought'. The authors identify examples of translanguaging and examples of translation which can be built on as part of teacher education so that teachers know how to use a translanguaging pedagogy which includes strategic use of translation, rather than the ad hoc translation that the coaches described in the interviews.

\subsection{Discourse topic 3: 'There are many identities'}

NGO Centre manager: ok so there's no actual book they have to follow. We want to promote group work or leadership or identifying identity. So these are the themes they try to link to the course that's the coaches' responsibility to assess the group that registered for this course let's say for English and he has a theme like identity 
so if the group is a basic level they will for example there are many identities in the community there's doctors there's police officers there's nationalities. If it is intermediate level they will go deeper, we have a bank which kinds of people work in a bank accountants etc. Ok what kinds of countries so they will go in deeper conversation about that subject matter depending on the course they choose. So the identity will be the same for barbering, so the barbering will say what's the barbering identity what's making a barbering do what he do.

NGO staff and coaches oriented to a dominant discourse about psycho-social support and respecting different identities. However, nowhere in the interviews was there a link between the beneficiaries' identities and language use. Knowledge about the links between language and developing a sense of where we belong in the world, and how we fit into the world, was missing.

\subsection{Discourse topic 4: In my eyes or in my movements, $i$ will show to her or to him that i am here to support}

Usman: In English classrooms when I will show my psycho-social support for everyone, firstly I will play with my body to show them I am with you, in my eyes or in my movements, I will show to her or to him that I am here to support you, to learn, to teach you to be with you don't shame with me. I am here just for you. If I see that she or he have a type of acceptance of my movements I try to be close for him or for her and sometimes it results in better attitude when there's a reaction and they become active.

The final discourse topic relates to using movement in the classroom to teach and to support. Above, Usman signals an understanding of how semiotic repertoires are not limited to the linguistic but rather include aspects of communication not always thought of as language. As in the example above, these include gesture and posture. Blackledge et al. (2015) explain how these semiotic repertoires are a record of mobility and experience and include gaps and silences as they are responding to the places and people to which a wide range of semiotic resources are deployed. These authors suggest, as illustrated in in Usman's description above, that the manner in which people walk, stand and sit, as well as the gaze of their eyes and the movements they make with their bodies, all make up the semiotic repertoire. In this sense, embodied communicative practices are part of linguistic communicative practice (Blackledge and Creese 2017). Similarly, Hua et al. argue that these multimodalities of movement, touch, gesture, gesture, objects and sounds, as well as other modes of communication in addition to the use of words, 'afford new translanguaging spaces and resources for multilingual and multimodal communication’ (Hua et al. 2015: 10.) 


\section{Discussion: Collaborating with NGOs to develop safe spaces for translanguaging for displaced learners}

All the teachers to varying degrees claimed that they tried to apply the 'English first' strategy, though they also acknowledged significant mixing of languages both inside and outside the classroom. This strategy clashes with what the beneficiaries reported doing in actual practice: language mixing or translanguaging. Teachers often produced complicated explanations when explaining what I saw them do during classroom observation and what they reported in the interviews. This is again a common mismatch between actual practice and reported practice, but it points towards what Cenoz and Gorter (2017: 903) describe as 'spontaneous translanguaging', which refers to the complex discourse practices of bilinguals (Garcia 2009). In my observations around the NGO outside the language classrooms, language mixing did not seem problematic as many Kurdish speaking and Arabic speaking beneficiaries and teachers seemed to be able to engage in complex interactions, making use of a large variety of resources by drawing on their trans-local, trans-cultural and translingual knowledge. What seemed to be problematic for the coaches was how they made sense of these complex practices in this superdiverse setting. Their attempts to make sense of these competing discourses can be seen in the tension between the 'English first' discourse and the 'translation as default' discourse. These discourses are in conflict with the importance that is given to psychosocial support, which is encouraged and illustrated in the social cohesion of the 'identities' and 'movement' discourses.

The classrooms described in the interview extracts above are increasingly multilingual with both teachers and learners exposed to different forms and varieties of Arabic and Kurdish, as well as English. The coaches spoke of feeling they needed to stick to English throughout the lesson, translating only as a means of moving the lesson forward, not using grammar and feeling as though the language mixing which came naturally to their learners was something to be avoided. These beliefs demonstrate a fundamental misunderstanding about language and learning and a mismatch between language mixing outside the classroom and what goes on inside it. All of the coaches demonstrated a lack of understanding about how to deal with classroom multilingualism and how best to draw on this diversity when teaching English, as well as when providing psycho-social support to their vulnerable learners. The findings also demonstrate that although there are parallels with English language teaching in other 
settings, there are also important differences, as the analysis shows. Ideas from TEFL, such as 'full immersion' and 'avoiding language interference', may make sense in other settings, but they are not helpful in the specific settings discussed in this paper, given the nature of the psycho-social support that is prioritised over teaching of the target language. In this final discussion it would seem that some of the commonly held beliefs by the coaches clash with what is now known about the complexities of learning in superdiverse settings such as Erbil.

As discussed earlier, Cenoz and Gorter (2017: 910) suggest that translanguaging has been used to describe different multilingual practices in different educational contexts (Lewis, Jones and Baker 2012; Garcia and Wei 2014). They suggest that this is a positive feature of translanguaging 'because it opens up new ways of looking at multilingual speakers and emergent multilinguals using a multilingual lens instead of [a] traditional monolingual perspective' (Cenoz and Gorter 2017: 910) and stress the importance of considering the specific characteristics of the socio-linguistic context when discussing its use in celebrating regional minority languages. They suggest that translanguaging in these contexts will only be sustainable if it is rooted in the reality of minority languages and allows for breathing spaces that create the need to use these languages. Hence, the authors have suggested building on Fishman's work (1991) on breathing spaces for use in schools where 'the idea is that the minority language can be used freely and without threat to the majority language; it can 'breathe', in a space where only the minority is spoken' (Cenoz and Gorter 2017: 910). Such a space, they suggest, could be a village, an area, a classroom or a school. Without using the term 'breathing spaces' the need for separate spaces has also been highlighted by Garcia (2009: 301) when discussing minority languages, and she says that 'it is important to preserve a space, although not a rigid or static place, in which the minority language does not compete with the majority language' (Cenoz and Gorter 2017: 909). Here I am suggesting that this principle of a breathing space be extended by bringing it together with the notions of a translanguaging space and a safe space. This can, I argue, only happen with the will of NGO language planners and policymakers. Policymakers have increasingly taken up the term superdiversity as a useful means of conceptualizing the challenges and affordances they engage with in planning to meet the needs of complex societies (Berg and Signona 2013). Superdiversity has begun to make a difference in policy in a range of areas, including educational policy and practice. However, exploring refugee settings as superdiverse, and seeing safe spaces in refugee settings as translanguaging spaces, remains an innovative yet useful lens, I argue, to view these diversification processes.

It was by examining how the heightened mobility of refugee settings as superdiverse in the first section of this paper that provided policymakers with 
evidence that essentialist and ethnicist views are no longer valid in understanding the more relational and fluid approach to communities and enterprise suggested by Ram et al. (2011). The essentialist discourses that emerged from the analysis in the previous section illustrate this. The fluidity of language practices outside the classroom setting is contrasted against the rigid monolingual practices of the coaches' classroom discourse. Just as the initial report on Language for Resilience was aimed at donors, planners and policymakers, the recommendation here is that continuing collaborations must be developed with the NGO sector, as 'trusting them as partners, goes some way to reduce the gap between the separate constituencies' (Blackledge et al. 2017: 8) in order to share with them learning from across the sociolinguistic study of migration and multilingualism. Given that Clayton's review of the literature on language learning and Post-traumatic Stress Disorder (PTSD) concluded that PTSD has a direct effect on refugee language learning (2015), teacher education which enables NGO language coaches to create translanguaging spaces as safe spaces in their provision of psycho-social support is an urgent need in the NGO sector. For example, this training could be included, initially, as part of the post-stress attunement training the coaches receive. Once the principles of a translanguaging space were embedded in the coaches' classroom practices additional support could be provided, adding to the coaches' knowledge of the role of language in learning.

\section{Conclusion}

This paper has introduced the concept of translanguaging to the study of complex superdiverse settings in locations which are characterised by heightened mobility because, it is claimed:

Superdiversity research has considerable potential to investigate, configure, theorise, and plan for greater equality in complex societies. In order to do so it will need to keep its balance, challenging established discriminatory structures, while at the same time going beyond those structures to reveal them as social and discursive constructions. This is a balancing act that requires social researchers with an interest in contributing to the creation of more equal societies to step into each others' academic territories, and exchange knowledge and expertise. It requires an approach that is interdisciplinary, or transdisciplinary. (Blackledge et al. 2017: 9)

Displaced people flee their country of origin for many reasons. These reasons profoundly shape the ways in which they settle, and the ways in which they draw on their language resources in these processes of settlement, however 
temporary. The paper presented here has sought to engage with the emerging literature on superdiversity to assess the possibilities for investigating language learning and displacement through its lens. It did this first by looking across the four countries neighbouring Syria as a means to balance the different views of the humanitarian staff working in these complex settings, and second by drawing from different disciplines when putting together a theoretical framework for the study of one specific NGO in Erbil, Kurdistan. The notion of a 'safe space' which is a key feature of the psycho-social support provided by humanitarian agencies was brought together with the concept of a translanguaging space, before exploring the notion of home language use in the interview data with coaches of English in the NGO. The language mixing which went on inside and outside classrooms, and the discourses that the coaches drew on to explain these practices, was at odds with the goal of teaching English as part of the provision of psycho-social support. This not only suggests that there is a misunderstanding about how language learning occurs but also that the emotional dialogue which NGO staff seek to encourage between the beneficiaries may in fact be negated by using a language in these programmes which is unfamiliar to the learners.

The Syrian refugee teacher and their Kurdish counterparts in the study provided could, for example, have spent their two-week 'English for teachers' course learning how to harness the translingual, trans-cultural practices of their diverse learners and reflected on a pedagogic approach in which all language varieties were valued. Instead, they focused entirely on English in the classroom and the level they achieved was not enough to teach any of the four skills, other than some basic vocabulary. If in the same period they had been able to work in their home language and developed a translanguaging pedagogy which fostered peer-to-peer learning, or translanguaging as co-learning (Wei 2017), they would then have been equipped with the kind of skills necessary for developing emotional dialogue through psycho-social support more relevant to the aims of the post-stress attunement programme that the NGO provides. The training for this post-stress attunement can therefore be the vehicle for training about translanguaging space as safe space, reaching NGO coaches as well as NGO management.

Given the levels of mobility in Iraq and across the region discussed here, taking this translanguaging approach or at least initially including breathing spaces for translanguaging, would be a step towards recognising the heightened complexity that the lens of superdiversity engages with and the increasingly stratified and multiple processes and effects of migration which lead to that heightened complexity (Vertovec 2015). How displaced people communicate when they bring their different histories and repertoires together in this 
complexity can be seen in their translanguaging when this is seen as 'the full deployment of a speaker's full linguistic repertoire without regard for watchful adherence to the socially and politically defined boundaries of named (and usually national and state) languages (Reid 2015: 281), which this paper suggests is even more pressing in times of political conflict. Moreover, the monolingual norm that was described in the majority of classroom settings for this study limits the possibilities for the kind of emotional dialogue that many NGOs seek to provide when engaging with displaced people across a region in which millions of people have been forced from their homes.

\section{References}

Ager, A., G. Burnham, F. Checchi, M. Gayer, R. Grais, M. Henkens, M. B. Massaquoi, R. Nandy, C. Navarro-Colorado \& P. Spiegel. 2014. Strengthening the evidence base for health programming in humanitarian crises. Science 345. 1290-1292.

Author, T. \& M. Delaney. 2016. Language for resilience. London: British Council.

Berg, M. L. \& N. Sigona. 2013. Ethnography, diversity, and urban space. Identities 30(4). 347-360. Blackledge, A. \& A. Creese. 2017. Translanguaging and the body. International Journal of Multilingualism 1747-7530.

Blackledge, A., \& A Creese 2017. Translanguaging and the body. International Journal of Multilingualism, 14(3),250-268.

Blackledge, A., A. Creese \& R. Hu. 2015. Voice and social relations in a city market. Birmingham: Working Papers in Translanguaging and Translation (WP2).

Blanchet, K., V. Sistenich, A. Ramesh, S. Frison, E. Warren, J. Smith, M. Hossain, A. Knight, C. Lewis, N. Post, A. Woodward, A. Ruby, M. Dahab, S. Pantuliano \& B. Roberts. 2015. An evidence review of research on health interventions in humanitarian crises. London: London School of Hygiene \& Tropical Medicine, Harvard School of Public Health \& Overseas Development Institute.

Blommaert, J. 2010. The sociolinguistics of globalization. Cambridge: Cambridge University Press. Blommaert, J. \& B. Rampton. 2011. Language and superdiversity. Diversities 13(2). 1-22.

Blommaert, J., M. Spotti \& J. Van der Aa. 2017. Complexity, mobility, migration. In R. Borrell (ed.), A review of second language learning factors for refugee populations, University of Minnesota. Retrieved from https://serranovillageconversation.weebly.com/uploads/2/9/ 3/0/29308213/borrell.pdf.

Blommaert, J, Massimiliano Spotti, \& Jef Van der Aa. 2017. Complexity, mobility, migration. The Routledge handbook of migration and language 349-363.

Canagarajah, S. (ed.). 2017. The routledge handbook of migration and language. London \& New York: Routledge, 349-363.

Cenoz, J., \& A. Gorter. 2017. Minority languages and sustainable translanguaging: threat or opportunity?. Journal of Multilingual and Multicultural Development, 38(10),901-912.

Clarke, M. A. 1976. Second language acquisition as a clash of consciousness. Language Learning 26(2). 377-390. 
Clayton, M. 2015. The Impact of PTSD on Refugee Learners available at file://C:/Users/ gt912774/Downloads/CLAYTON_2015_REFUGEE_PTSD_LITREV.pdf accessed 3 February 2016

Conteh, J., \& A. Brock. 2011. Safe spaces'? Sites of bilingualism for young learners in home, school and community. International Journal of Bilingual Education and Bilingualism, 14 (3), 347-360.

Copland, F. \& A. Creese. 2015. Linguistic ethnography. Collecting, analyzing and presenting data. London: Sage.

Costa, Beverley \& Jean-Marc Dewaele. 2013. Psychotherapy across languages: beliefs, attitudes and practices of monolingual and multilingual therapists with their multilingual patients. Counselling and Psychotherapy Research 14. doi:10.1002/14733145.2013.838338

Cummins, J. 2001. Negotiating identities: Education for empowerment in a diverse society. 2nd ed. Los Angeles: California Association for Bilingual Education.

De Fina, A., D. Ikizoglu \& J. Wegner. 2017. Introduction. In A. De Fina, D. Ikizoglu \& J. Wegner (eds.), Diversity and super-diversity sociocultural linguistic perspectives. Washington DC: Georgetown University Press vii-xii.

Dijk, Van \& Teun Adrianus. 1984. Prejudice in discourse: An analysis of ethnic prejudice in cognition and conversation. Amsterdam: J. Benjamins Co.

Duchêne, Alexandre, Melissa Moyer \& Celia Roberts (eds.), 2013. New York: Multilingual matters.

Fishman, J. A. 1991. Reversing language shift: Theoretical and empirical foundations of assistance to threatened languages (Vol. 76). Multilingual matters.

Footitt, H., \& Kelly, M. (ads.). 2012. Languages at war: Policies and practices of language contacts in conflict. Springer.

García, 0. 2009. Bilingual education in the twenty-first century: A global perspective. West Sussex, UK: Wiley-Blackwell.

García, O. \& L. Wei. 2014. Translanguaging: Language, bilingualism and education. Basingstoke: Palgrave Macmillan.

Gordon, D. 2011. Trauma and second language learning among laotian refugees. Journal of Southeast Asian American Education and Advancement 6. Article 13. doi:10.7771/2153-8999.1029. Retrieved from https://docs.lib.purdue.edu/jsaaea/vol6/iss1/13 (accessed 23 March 2018).

Gumperz, J. J. 1982. Discourse strategies. Cambridge: Cambridge University Press.

Heller, M. 2007. Distributed knowledge, distributed power: A sociolinguistics of structuration. Text and Talk 27(5-6). 633-653.

Heller, M. 2010. Linguistic commodification. Annual Review of Anthropology 39. 101-114.

Heller, M. 2011. Paths to post-nationalism: A critical ethnography of language and identity. Oxford: Oxford University Press.

Horwitz, E.K. 2000. It ain't over 'til it's over: on foreign language anxiety, first language deficits and the 593 confounding of variables. The Modern Language Journal 84. 256-259.

Hua, Zhu, Li Wei \& A. Lyons. 2015. Language, business and superdiversity in London: Translanguaging business. Working Papers in Translanguaging and Translation (WP. 5). http://www.birmingham.ac.uk/generic/tlang/index.aspx

Hundeide, K. 2013. An introduction to the ICDP Programme. http://www.icdp.info/var/ uploaded/2013/04/2013-04-11_01-49-56_an_introduction_to_the_icdp_programme.pdf (15 May, 2017).

Hymes, D. H. 1980. Language in Education: Ethnolinguistic Essays. Language and Ethnography Series. Center for Applied Linguistics, 3520 Prospect Street, NW, Washington, DC 20007. 
Krzyzanowski, M. (2008). Analysing focus group discussions. In R. Wodak \& M. Krzyzanowski (Eds), Qualitative discourse analysis in the socials sciences (pp. 162-181). Basingstoke: Palgrave Macmillan. http://ifa.amu.edu.pl/publications/biblio/author/Krzy\%C5\% BCanowski

Lewis, G., Jones, B., \& Baker, C. 2012. Translanguaging: Origins and development from school to street and beyond. Educational Research and Evaluation, 18(7), 641-654.

Macphail, J., M. Niconchuk \& N. El-Wer. 2017. Conflict, the brain, and community: A neurobiology-informed approach to resilience and community development. In R. Phillips, S. Kenny \& B. McGrath (eds.), The Routledge handbook of community development perspectives from around the globe, 340-357. London: Taylor \& Francis Ltd..

Makalela, L. 2017. Translanguaging practices in a South African institution of higher learning: A case of Ubuntu multilingual return. In C. Mazak \& K. Carroll (eds.), Translanguaging in higher education. Beyond monolingual ideologies. Bristol: Multilingual Matters.

Martin Rojo, L. 2010. Constructing inequality in multilingual classrooms. Berlin: Mouton de Grutyer.

Mufwene, Salikoko S. 2008. Language evolution: Contact competition, and change. London: Continuum Press.

Ndhlovu, F. 2016. A decolonial critique of diaspora identity theories and the notion of superdiversity. Diaspora Studies 9(1). 28-4.

Panter-Brick, C., R. Dajani, M. Eggerman, S. Hermosilla, A. Sancilio \& A. Ager. 2017. Insecurity, distress and mental health: experimental and randomized controlled trials of a psychosocial intervention for youth affected by the Syrian crisis. Journal of Child Psychology and Psychiatry.

Panter-Brick, C., Dajani, R., Eggerman, M., Hermosilla, S., Sancilio, A., \& Ager, A. 2018. Insecurity, distress and mental health: experimental and randomized controlled trials of a psychosocial intervention for youth affected by the Syrian crisis. Journal of Child Psychology and Psychiatry, 59(5), 523-541.

Patel, V. 2014. Rethinking mental health care: Bridging the credibility gap. Intervention 12. 15-20. Pavlenko, A. 2016. Superdiversity and why it isn't. In S. Breidbach, L. Kuster \& B. Schmenk (eds.), Sloganizations in language education discourse. PuBristol, UK: Multilingual Matters.

Pennycook, A. \& E. Otsuji. 2015. Metrolingualism. Language in the City. London: Routledge. Pennycook, Alastair. 2012. Language and mobility: Unexpected places. Bristol: Multilingual Matters.

Pérez-Milans, M. 2015. Language education policy in late modernity. (Socio)linguistic ethnographies in the European Union. Language Policy 14(2). 99-108.

Phillimore, J. 2015. Embedded integration and organisational change in housing providers in the UK. Social Policy and Society 16. 1-14.

Piller, I., \& K. Takahashi. 2011. Linguistic diversity and social inclusion. International Journal of Bilingual Education and Bilingualism, 14(4),371-381.

Ram, M., P. Edwards, T. Jones, A. Kiselinchev, L. Muchenje \& K. Woldesenbet. 2011. Engaging with super-diversity: New migrant businesses and the research-policy nexus. International Small Business Journal 31(4). 337-35.

Rampton, B. 2006. Language in Late Modernity. Cambridge: Cambridge University Press.

Reid, W. 1991. Verb and noun number in English : A functional explanation. London \& New York: Longman Publishers.

Reisigl, Martin \& Ruth Wodak. 2001. Discourse and Discrimination. London: Routledge. 
Shanks, Kelsey. 2016. The changing role of education in the Iraqi disputed territories: assimilation, segregation and indoctrination. Globalisation, Societies and Education 14.3 (2016): 422-433.

Smith, M. P. 2003. Transnationalism, the state, and the extraterritorial citizen. Politics \& Society,31 (4), 467-502.

Sutherland, M. 1997. Using storytelling as a therapeutic tool with children. Speechmark Publishing.

Tol, W., C. Barbui, A. Galappatti, D. Silove, T. Betancourt, R. Souza, A. Golaz \& M. van Ommeren. 2011. Mental health and psychosocial support in humanitarian settings: linking practice and research. Lancet 378. 1581-1591.

UNESCO, P. 2003. Education in a multilingual world. Guidelines in Language and Education.

UNHCR. 2016. Global trends: Forced displacement in 2015. Geneva, Switzerland: UNHCR.

UNHCR. 2017. Syrian regional refugee response in Jordan. https://data.unhcr.org/syrianrefu gees/country. php?id=107

UNICEF. 2016. Language education and social cohesion (LESC) Initiative. Malaysia: UNICEF East Asia and Pacific Regional Office.

Vertovec, S. 2015. Introduction: migration, cities, diversities 'old' and 'new'. In S. Vertovec (ed.), Diversities old and new: Migration and socio-spatial patterns in New York, Singapore and Johannesburg, 1-20. New York: Palgrave Macmillan.

Wei, Li. 2011. Moment analysis and translanguaging space: Discursive construction of identities by multilingual Chinese youth in Britain. Journal of Pragmatics 43(5). 1222-1235.

Wei, Li. 2017. Translanguaging as a practical theory of language. Applied Linguistics 23.

Wei, L. 2017. Translanguaging as a practical theory of language. Applied Linguistics, 39 (1),9-30.

Wodak, R \& Martin Reisigl. 2003. 19 Discourse and Racism. The handbook of discourse analysis 18 (2003): 372.

Zheng, Y. 2008. Anxiety and second/foreign language learning revisited. Canadian Journal for New Scholars in Education 1(1). 1-12. Available on line at https://files.eric.ed.gov/fulltext/ ED506736.pdf. 